\title{
Predicting and preventing autoimmunity: the case of anti-mitochondrial antibodies
}

\author{
Malgorzata Milkiewicz • Llorenç Caballería • \\ Daniel S. Smyk • Piotr Milkiewicz
}

Received: 22 September 2012/ Accepted: 3 October 2012/Published online: 16 October 2012

(C) Springer-Verlag Italia 2012

\begin{abstract}
To be able to predict who will develop autoimmune disease would allow for early treatment which may dramatically alter the course of the disease. In some cases, it may also lead to prevention of the disease development. The prediction of disease development is based on the analysis of risk factors which have been associated with the disease in question. These factors include genetic susceptibility, as well as immunological and environmental factors. One autoimmune disease that may serve as a model for disease prediction is primary biliary cirrhosis (PBC), an autoimmune liver disease affecting the small- and mediumsized bile ducts. PBC could be an ideal model due to recent advances in elucidating its genetic associations. As well, a variety of immunological and environmental risk factors have been well established. Indeed, the presence of PBCspecific antimitochondrial antibodies and/or antinuclear antibodies has been shown to be predictor of disease development and possibly prognosis. This review will
\end{abstract}

M. Milkiewicz

Medical Biology Laboratory, Pomeranian Medical University,

Szczecin, Poland

L. Caballería

Liver Unit, Hospital Clínic University of Barcelona,

Barcelona, Spain

D. S. Smyk

Institute of Liver Studies, King's College London School

of Medicine, London, UK

P. Milkiewicz $(\bowtie)$

Liver Unit, Pomeranian Medical University,

Al. Powstancow Wlkp. 72, 70-111 Szczecin, Poland

e-mail: milkiewp@sci.pum.edu.pl examine the current evidence which suggests that we may potentially be able to predict the development of PBC in some individuals. These concepts may also be applied to autoimmune diseases in general.

Keywords Autoimmunity - Autoimmune disease . Genetics · Prevention · Prediction · Risk factor . Susceptibility

$\begin{array}{ll}\text { Abbreviations } & \\ \text { AMA } & \text { Antimitochondrial antibodies } \\ \text { ANA } & \text { Antinuclear antibodies } \\ \text { E. coli } & \text { Escherichia coli } \\ \text { L. delbrueckii } & \text { Lactobacillus delbrueckii } \\ \text { PBC } & \text { Primary biliary cirrhosis } \\ \text { PDC-E2 } & \text { Pyruvate dehydrogenase complex } \\ \text { UTI } & \text { Urinary tract infection }\end{array}$

\section{Introduction}

Primary biliary cirrhosis (PBC) is a chronic cholestatic liver disease characterised by immune-mediated destruction of the small- and medium-sized intrahepatic bile ducts, which in many individuals may progress to cirrhosis and liver failure [1, 2]. In advanced cases, transplantation may be required. At the time of diagnosis, patients may be symptomatic or asymptomatic, with asymptomatic patients having normal or abnormal biochemistry tests, possibly with cholestatic indices being raised [1-6]. Symptomatic patients typically present with non-specific symptoms such as fatigue, pruritus and arthralgias, with liver disease not being suspected initially 
[1-6]. It is not uncommon for PBC patients to have had several non-hepatological investigations and consultations for their symptomatology. In advanced stages of the disease, patients may present with complications from portal hypertension and hepatic decompensation, such as jaundice, ascites or variceal bleeding [1-6]. Although there may be great variation in the presenting signs and symptoms, the commonality found among patients are the presence of anti-mitochondrial (AMA) or disease-specific antinuclear antibody (ANA), which are present in almost all patients [7-9]. In order to establish the diagnosis a patient has to fulfil two from the three criteria mentioned below: elevated alkaline phosphatase (ALP), seropositivity for disease-specific AMA and/or ANA, as well as specific histological features of $\operatorname{PBC}[1,5,6]$. Histological features of PBC are destruction of the biliary epithelial cells, ductopaenia, portal inflammatory cell infiltration, as well as granuloma formation [1, 2]. Cholestatic markers include increased levels of alkaline phosphatase and $\gamma \mathrm{GT}$ $[1-6,10]$. PBC is a slowly progressive disease, with the clinical course being well known as unpredictable [1-6, 10]. Medical treatment of PBC is with ursodeoxycholic acid (UDCA) administered at an appropriate dose (13-15 mg/kg/day) [1-6]. Early administration of UDCA slows the disease progression and has improved the quality of life in many patients [1-6, 11].

Epidemiological studies from the USA, UK and France have established several risk factors to be associated with PBC development [12-15]. Although risk factors vary among the studies, recurrent urinary tract infection, a history of smoking and oestrogen disturbance have been found to be risks in all studies. Female sex as well as being a first degree relative to a patient with PBC also increases the risk for disease development [12-15]. In recent years, genetic and genome wide association studies (GWAS) have identified several disease genes to be associated with PBC. A combination of genetic and environmental factors likely work together in the development of the disease.

Currently, no reliable prognostic index has been developed which can predict the course of the disease and its outcome over time in patients at early stages [1, 3-6]. However, given that several risk factors have been identified, the question remains as to whether we can predict the development of PBC in some individuals. Indeed, this question is raised not only with $\mathrm{PBC}$, but with all autoimmune diseases in general. If we can predict the development of $\mathrm{PBC}$, it may be possible to prevent disease development in some or detect the disease early in others. This review will examine the known risk factors for PBC development, in an attempt to analyse whether PBC development is predictable in certain individuals. This approach with $\mathrm{PBC}$ would perhaps be applied to other autoimmune diseases.

\section{PBC-specific autoantibodies as prognosticators of disease's development}

AMA are pathognomic for $\mathrm{PBC}$ as they are present in up to $95 \%$ of PBC patients, and their presence in asymptomatic individuals is generally believed to precipitate eventual disease development [1-9, 16-18]. Several studies indicate that the prevalence of AMA in the general population is $<1 \%$ [19-21]. In PBC patients, AMA react against components of the 2-oxo-acid dehydrogenase complexes and mostly recognise the E2 subunit of the pyruvate dehydrogenase complex (PDC) [1, 2, 9, 16-18, 22-26]. AMA are reactive against PDC-E2 in more than $90 \%$ of cases, and there is also cross-reactivity with the PDC-E3 binding protein (E3BP) [27-29]. Other targets (in 20-70\% of cases) include the E2 subunits of branched-chain 2-oxoacid dehydrogenase complex (BCOADC) and 2-oxoglutarate dehydrogenase complex (OGDC) and the $\mathrm{E} 1 \alpha$ and $\mathrm{E} 1 \beta$ subunits of PDC [1, 7, 8, 24, 26-29].

The Newcastle group has studied the significance of AMA in detail, and they indicate that the majority of asymptomatic, non-cholestatic patients positive for AMA, have histological features of PBC [23, 30]. Their first study included 29 patients with positive AMA (greater than 1/40 titer by indirect IFL), who were asymptomatic for liver disease [23]. The average age of the cohort was 54.7 years, 28 patients were females, and one set consisted of a mother-daughter pair [23]. All patients had normal LFTs, although raised $\gamma$-GT levels were found in 14 individuals [23]. Ten patients had elevated IgM levels, and 2 had marginally raised $\mathrm{IgG}$, with an IgG subclass distribution of the AMA being primarily IgG3 followed by IgG1 [23]. Histological examination of liver biopsies demonstrated that 12 individuals had changes compatible with PBC, including inflammatory cell infiltrates around damaged bile ducts with and without macrophage granulomata in the portal tracts [23]. Twelve had non-specific chronic hepatitis around bile ducts or lymphoid aggregates within the portal areas [23]. Mild fibrosis was found in seven biopsies, and only two biopsies in the entire cohort were completely normal [23]. After a mean 8.7-year follow-up, one patient had died of post-cricoid carcinoma, and five developed PBC symptoms (unexplained pruritus with malaise or malaise alone) [23]. Two of 13 patients followed-up for $<4$ years had developed pruritus, and 12 of 16 (all female) followed up for more than 4 years had developed abnormal LFTs [23]. These results led those authors to conclude that AMA positivity in the absence of symptoms, with or without normal liver disease-related biochemistry, is predictive of future PBC development, and many of these patients may already have histological evidence of early PBC [23]. The same group followed up the same cohort 10 years later [30]. The median follow-up of those patients 
was 17.8 years, ranging from 11-23.9 years, although five of the original patients had died from non-liver-related causes [30]. PBC symptoms had developed in 22 of 24 patients $(76 \%)$, which included pruritus, ongoing fatigue, and chronic right upper quadrant pain [30]. Persistently cholestatic LFTs were reported in 24 patients (83\%) [30]. Repeat liver biopsy material was available in ten patients and showed fibrosis progression from grade 1 to 2 in two individuals, and progression from grade 2 to 3 in another two [30]. Cirrhosis had not developed in any of the patients [30]. ELISA of baseline serum samples demonstrated positive AMA in 21 of 27, all of which had initial biopsy results compatible with $\mathrm{PBC}$, confirming the presence of $\mathrm{PBC}$ in asymptomatic, non-cholestatic patients with positive AMA [30].

A study of another cohort has produced similar results. Kisand and colleagues [19] conducted an ELISA-based study for antibodies to PDC-E2, the major PBC-specific autoantigen, in three groups of Estonian patients. The first group consisted of 1,461 individuals (ages 15-95 years, mean 41 years, 637 males and 824 females), the second 497 individuals (ages 50-91 years, mean 61 years, 189 males and 308 females), and a third of 104 volunteers from neighbouring small villages (mean age 42 years, 29 males and 75 females) [19]. Fourteen individuals were found to have antibodies to PDC-E2, all of which were asymptomatic [19]. These patients were followed-up at 2, 4, 7 and 9 years [19]. Eight of the 14 were available for follow-up, and 3 of the 8 had developed abnormal LFTs by the 9th year of follow-up [19]. These patients also had AMA detectable on indirect IFL, had inhibitory antibodies to PDC and had anti-PDC of the $\operatorname{IgG}$ and IgA subclass, although the IgG subclass was predominant [19]. The remaining five AMA positive patients had low titer positivity, remained positive for AMA on follow-up, but did not develop any evidence of cholestasis [19]. Unfortunately, liver biopsies were not performed in any patients, apparently due to lack of consent [19]. The above studies demonstrate the strong predictive value of AMA positivity for future PBC development.

ANA are also found in $\mathrm{PBC}$, and their presence suggests a more progressive form of the disease $[1,7,8,24,26-29$, 31-41]. Several PBC-specific ANA patterns have been identified by indirect immunofluorescence (IFL). These include the "multiple nuclear dot" and "nuclear membrane/rim like" patterns [7, 8, 42, 43]. The "multiple nuclear dot" pattern relates to autoantibodies against Sp100, Sp140, promyelocytic leukaemia nuclear body proteins and small ubiquitin-like modifiers $[1,7,8,24,26-$ 29, 31-35]. The "nuclear envelope/rim like" pattern relates to reactivities specific for gp210 and nucleoporin p62 [42]. Both patterns show disease specificity and are present in approximately $30 \%$ of patients. These ANA may also be present in patients who are AMA negative, in addition to asymptomatic individuals and family members of PBC patients [8, 17, 31-35, 44, 45].

The initiating events leading to AMA/ANA seropositivity, as well as the pathological role of these autoantibodies, remain unknown [1, 44, 46-49]. It has been suggested that impaired T-regulation, apoptosis-mediated autoimmune attack, xenobiotics-induced cellular destruction and molecular mimicry and immunological cross-reactivity may account for the development of autoantibodies [50-85]. Experimentally, numerical and/or functional impairment of regulatory $\mathrm{T}$ cells has been demonstrated in PBC [55, 65-67, 86-89]. Apoptotic blebs of biliary epithelial cells have been shown to contain intact immunoreactive mitochondrial autoantigens, indicating a role for apoptosis in mediating tissue-specific injury in PBC [1, 46, 47, 64]. The method with which xenobiotics may induce the formation of autoantibodies is similar to that seen in microbial/self molecular mimicry $[1,75,76]$. Molecular mimicry occurs when antigenic similarities between microbial or viral antigens and self-targets lead to the induction of cross-reactive immune responses targeting both microbial and self-epitopic regions $[1,7,26,46,49-54,56,58,59,63,68,70-72,83,90]$. The immune attack against self targets may initiate a selfperpetuating progressive inflammation and destruction of the biliary epithelial cells $[1,7,26,46,49-54,56,58,59$, $63,68,70-72,83,91]$. A variety of environmental and infectious agents, as well as immunological and genetic factors have been suggested as potential triggers for the induction of PBC-specific antibodies[50-54, 58, 59, 64, 73-83, 86-89].

The prevalence of AMA, and perhaps to a lesser extent PBC-specific ANA, may be useful in the identification of individuals at risk of PBC development. This is especially the case in first-degree relatives of PBC patients, with female relatives being at higher risk than others. Indeed, the most common familial pairing in $\mathrm{PBC}$ is seen in mother-daughter and sister pairs [92-95]. Therefore, the screening of these individuals for disease-specific autoantibodies may identify those asymptomatic ones who are likely to go on to develop PBC. Further screening of these patients for markers of cholestasis would be recommended, as would early treatment.

\section{Genetics}

Bianchi et al. in this special issue discusses in great detail the influence of environment and genetics in the development of PBC. It appears that female relatives of PBC patients have higher risk for PBC compared with demographically matched controls, which demonstrates the likelihood of genetic factors being involved in the disease 
development [90, 96-101]. The female preponderance of the disease may be due to genetic factors affecting the $\mathrm{X}$ chromosome, as a higher frequency of monosomy $\mathrm{X}$ in peripheral leukocytes has been found in patients with $\mathrm{PBC}$ [62, 102-106]. A single study in twins demonstrated a high concordance among monozygotic twins and a low concordance among dizygotic twins [107]. Genetic association studies (GWAS) have identified multiple gene loci to be associated with PBC, such as HLA DQB1, IL12A, IL12RB2, STAT4, CTLA4, IRF5-TNPO3, 17q12-21, and MMEL1, 17q12-21, DENND1B, CD80, IL7R, CXCR5, TNFRSF1A, CLEC16A and NFKB1 [108, 109, 110-113]. Although GWAS and other genetic studies provide us with a list of genetic associations, it is not clear as to how many of these associations are required for disease development. As well, there is no prognostic significance attached to these genetic associations although it is likely that future research will elucidate those genes which are responsible for fast versus slow disease progression. Genetic associations may also assist in the identification of those at higher risk of disease development, not only in PBC, but also in other conditions in which there is a strong genetic influence. Patients with a particular genetic trait (likely in combination with other clinical and demographic data) may be monitored for biochemical, immunological and clinical indices of disease development. As well, patients who have a susceptible trait may be advised in regard to risk reduction, such as hormonal therapy or smoking cessation and the aggressive treatment of recurrent UTI. All of these have been shown to be risk factors in PBC development [12-15, 114].

\section{Recurrent urinary tract infections}

Recurrent UTI has been indicated as a risk factor for PBC development [12-15, 94]. UTI was first suspected as a risk factor for $\mathrm{PBC}$ when investigators noted a higher incidence of bacteriuria in PBC patients compared with controls [115]. A study by Gershwin et al. [13] demonstrated that $59 \%$ of 1,032 PBC patients reported a history of UTI. Prince and colleagues [15] reported similar associations in a study involving one group of 318 PBC patients from a geographically defined area and another involving 2,258 patients from a PBC support group [15]. UTI and PBC were found to be associated in the multivariate analysis (in both PBC groups) but not in a cohort of 3,936 demographically matched controls [15].

As a major causative organism of UTI, E. coli has been identified as an organism of interest in PBC, and it has been suggested that molecular mimicry between human and E. coli PDC-E2 may be involved in the breakdown of tolerance to PDC-E2 [116, 117]. Molecular mimicry and immunological cross-reactivity between bacterial-self peptides has been investigated as a mechanism responsible for the induction of liver autoimmunity $[49,57,61,63$, 68-70, 91, 118-123]. At the experimental level, sera from PBC patients react with both E. coli and human PDC-E2. Also, more than half of the patients with recurrent UTI cross-recognize human PDC-E2 [124]. The significance of the disease-specific presence of antibodies against an ATP-dependent Clp protease of E. coli remains unclear [125-127]. Amino acid homologies between E. coli and human PDC-E2 sequences required for $\mathrm{T}$ cell epitope recognition of PDC-E2 have also been reported and pathogenic scenarios involving these epitopes in the pathogenesis of PBC have been formulated [119, 128]. Elegant studies have demonstrated that the E. coli and human PDC-E2 homologues are targets of cross-reactive responses at the CD4 T cell level [119, 129].

Several other organisms have been associated with PBC via a link with recurrent UTI, including Lactobacillus delbrueckii ( $L$. delbrueckii). Vaginitis and vaginal infections have been found to be prevalent among PBC patients, and the question arises as to whether these are due to L. delbrueckii, which is part of the normal flora of the vagina $[13,14]$. A pathogenic scenario implies that infections with $L$. delbrueckii increase susceptibility to vaginal infections, leading to recurrent UTI and subsequently PBC [130]. However, this hypothesis lacks experimental validation. Lactobacilli have also been linked to PBC development a 39-year-old female who received Lactobacilli vaccination for recurrent vaginitis [131]. The authors of this study have speculated that an immune response against Lactobacilli initiated a cross-reactive response targeting human PDC-E2 via a mechanism of molecular mimicry. The sera of the patient tested positive for AMA and the AMA targeting epitope from beta-galactosidase of Lactobacillus delbrueckii [131]. This is an interesting finding taking into account a previous report demonstrating that L. delbrueckii and human PDC-E2 share sequences in common which are targeted by antibodies specifically found in approximately $50 \%$ of patients with PBC [130]. The fact that $L$. delbrueckii is a cause of recurrent UTI in a considerable proportion of elderly women further supports the theory involving this infectious agent in the pathogenesis of PBC [132, 133].

Despite UTI being linked to PBC, it remained unclear as to whether this association was causal or casual, as changes in mucosal immunity may infer an increased susceptibility to UTI via alterations in vaginal flora. A recent study by Varyani and colleagues [134] found that UTI preceded the diagnosis of PBC in a cohort of PBC patients. That study involved 800 PBC patients, 7,991 matched controls and 12,137 patients with chronic liver disease as controls [134]. UTI had been diagnosed within 1 year prior to PBC 
diagnosis in $29 \%$ of PBC patients, in comparison with $22 \%$ of healthy controls and $17 \%$ of chronic liver disease controls [134]. UTI had been diagnosed in $19 \%$ of PBC patients within a 5-year period prior to $\mathrm{PBC}$ diagnosis, compared with $14 \%$ of matched controls and $11 \%$ chronic liver disease controls [134]. That study has demonstrated that in a large cohort of PBC patients, UTI does precede $\mathrm{PBC}$ diagnosis and therefore adds further evidence towards a potential role for molecular mimicry and cross reactivity. It also highlights that recurrent UTI may be a predicting factor of PBC development and may prompt aggressive antibiotic therapy for those who have further risk factors (such as family history, AMA positivity, or genetic traits).

\section{Conclusions}

To predict whether one will develop an autoimmune disease is as complex matter as the aetiology of the diseases themselves. The most important factors which must be taken into account are risk factors which have been associated with the disease and their additive effect within the individual. As with $\mathrm{PBC}$, it is unlikely that genetic associations can wholly predict the disease development, but a variety of other intrinsic and extrinsic factors must also be taken into account. AMA and/or ANA positivity, the disease-specific autoantibody markers, appear to have great predictive value in both disease development and prognosis, with a history of UTI adding to the likelihood of PBC development.

New high-throughput methods are now permitting rapid screening of hundreds of autoantibodies at an affordable cost. Screening of such autoantibodies with significant positive predictive value for specific autoimmune diseases, including those seen in patients with primary biliary cirrhosis, may become a routine part of medical management in the long run. The individuals screened for such autoantibodies will only be those who have HLA and non-HLA genes conferring susceptibility to specific autoimmune diseases, as detected by genetic screening. Close monitoring for evidence of exposure to specific environmental and infectious agents that increase the risk for the development of autoimmunity may assist in the clinical management of these cases. The benefit and cost savings of such practice will be tremendous once preventative methods and costeffective, targeted therapies become available.

\section{Conflict of interest None.}

\section{References}

1. Kaplan MM, Gershwin ME (2005) Primary biliary cirrhosis. N Engl J Med 353:1261-1273
2. Neuberger J (1997) Primary biliary cirrhosis. Lancet 350:875879

3. Hemminki K, Li X, Sundquist K et al (2009) Shared familial aggregation of susceptibility to autoimmune diseases. Arthritis Rheum 60:2845-2847

4. Kumagi T, Heathcote EJ (2008) Primary biliary cirrhosis. Orphanet J Rare Dis 3:1

5. Lindor KD, Gershwin ME, Poupon R et al (2009) Primary biliary cirrhosis. Hepatology 50:291-308

6. Poupon R (2010) Primary biliary cirrhosis: a 2010 update. J Hepatol 52:745-758

7. Bogdanos DP, Baum H, Vergani D (2003) Antimitochondrial and other autoantibodies. Clin Liver Dis 7:759-777, vi

8. Bogdanos DP, Invernizzi P, Mackay IR et al (2008) Autoimmune liver serology: current diagnostic and clinical challenges. World J Gastroenterol 14:3374-3387

9. Mackay IR (1958) Primary biliary cirrhosis showing a high titer of autoantibody; report of a case. N Engl J Med 258:185-188

10. Vleggaar FP, van Buuren HR, Zondervan PE et al (2001) Jaundice in non-cirrhotic primary biliary cirrhosis: the premature ductopenic variant. Gut 49:276-281

11. Hohenester S, Oude-Elferink RP, Beuers U (2009) Primary biliary cirrhosis. Semin Immunopathol 31:283-307

12. Corpechot C, Chretien Y, Chazouilleres O et al (2010) Demographic, lifestyle, medical and familial factors associated with primary biliary cirrhosis. J Hepatol 53:162-169

13. Gershwin ME, Selmi C, Worman HJ et al (2005) Risk factors and comorbidities in primary biliary cirrhosis: a controlled interviewbased study of 1032 patients. Hepatology 42:1194-1202

14. Parikh-Patel A, Gold EB, Worman H et al (2001) Risk factors for primary biliary cirrhosis in a cohort of patients from the united states. Hepatology 33:16-21

15. Prince MI, Ducker SJ, James OF (2010) Case-control studies of risk factors for primary biliary cirrhosis in two United Kingdom populations. Gut 59:508-512

16. Rigopoulou EI, Bogdanos DP, Liaskos C et al (2007) Antimitochondrial antibody immunofluorescent titres correlate with the number and intensity of immunoblot-detected mitochondrial bands in patients with primary biliary cirrhosis. Clin Chim Acta 380:118-121

17. Vergani D, Bogdanos DP (2003) Positive markers in AMAnegative PBC. Am J Gastroenterol 98:241-243

18. Walker JG, Doniach D, Roitt IM et al (1965) Serological tests in diagnosis of primary biliary cirrhosis. Lancet 1:827-831

19. Kisand KE, Metskula K, Kisand KV et al (2001) The follow-up of asymptomatic persons with antibodies to pyruvate dehydrogenase in adult population samples. J Gastroenterol 36:248-254

20. Mattalia A, Quaranta S, Leung PS et al (1998) Characterization of antimitochondrial antibodies in health adults. Hepatology 27:656-661

21. Tunbridge WM, Evered DC, Hall R et al (1977) The spectrum of thyroid disease in a community: the Whickham survey. Clin Endocrinol 7:481-493

22. Dahnrich C, Pares A, Caballeria L et al (2009) New ELISA for detecting primary biliary cirrhosis-specific antimitochondrial antibodies. Clin Chem 55:978-985

23. Mitchison HC, Bassendine MF, Hendrick A et al (1986) Positive antimitochondrial antibody but normal alkaline phosphatase: is this primary biliary cirrhosis? Hepatology 6:1279-1284

24. Leung PS, Coppel RL, Ansari A et al (1997) Antimitochondrial antibodies in primary biliary cirrhosis. Semin Liver Dis 17:61-69

25. Liu H, Norman GL, Shums Z et al (2010) PBC screen: an IgG/ IgA dual isotype ELISA detecting multiple mitochondrial and nuclear autoantibodies specific for primary biliary cirrhosis. J Autoimmun 35:436-442 
26. Van de Water J, Fregeau D, Davis P et al (1988) Autoantibodies of primary biliary cirrhosis recognize dihydrolipoamide acetyltransferase and inhibit enzyme function. J Immunol 141:2321-2324

27. Dubel L, Tanaka A, Leung PS et al (1999) Autoepitope mapping and reactivity of autoantibodies to the dihydrolipoamide dehydrogenase-binding protein (E3BP) and the glycine cleavage proteins in primary biliary cirrhosis. Hepatology 29:1013-1018

28. Palmer JM, Jones DE, Quinn J et al (1999) Characterization of the autoantibody responses to recombinant E3 binding protein (protein $\mathrm{X}$ ) of pyruvate dehydrogenase in primary biliary cirrhosis. Hepatology 30:21-26

29. Bogdanos DP, Vergani D (2006) Origin of cross-reactive autoimmunity in primary biliary cirrhosis. Liver Int 26:633-635

30. Metcalf JV, Mitchison HC, Palmer JM et al (1996) Natural history of early primary biliary cirrhosis. Lancet 348:1399-1402

31. Bogdanos DP, Liaskos C, Pares A et al (2007) Anti-gp210 antibody mirrors disease severity in primary biliary cirrhosis. Hepatology 45:1583; author reply 1583-1584

32. Invernizzi P, Podda M, Battezzati PM et al (2001) Autoantibodies against nuclear pore complexes are associated with more active and severe liver disease in primary biliary cirrhosis. J Hepatol 34:366-372

33. Miyachi K, Hankins RW, Matsushima $\mathrm{H}$ et al (2003) Profile and clinical significance of anti-nuclear envelope antibodies found in patients with primary biliary cirrhosis: a multicenter study. J Autoimmun 20:247-254

34. Nakamura M, Kondo H, Mori T et al (2007) Anti-gp210 and anti-centromere antibodies are different risk factors for the progression of primary biliary cirrhosis. Hepatology 45:118-127

35. Rigopoulou EI, Davies ET, Pares A et al (2005) Prevalence and clinical significance of isotype specific antinuclear antibodies in primary biliary cirrhosis. Gut 54:528-532

36. Itoh S, Ichida T, Yoshida T et al (1998) Autoantibodies against a $210 \mathrm{kDa}$ glycoprotein of the nuclear pore complex as a prognostic marker in patients with primary biliary cirrhosis. J Gastroenterol Hepatol 13:257-265

37. Lassoued K, Guilly MN, Andre C et al (1988) Autoantibodies to $200 \mathrm{kD}$ polypeptide(s) of the nuclear envelope: a new serologic marker of primary biliary cirrhosis. Clin Exp Immunol 74:283-288

38. Muratori P, Muratori L, Ferrari R et al (2003) Characterization and clinical impact of antinuclear antibodies in primary biliary cirrhosis. Am J Gastroenterol 98:431-437

39. Wesierska-Gadek J, Penner E, Battezzati PM et al (2006) Correlation of initial autoantibody profile and clinical outcome in primary biliary cirrhosis. Hepatology 43:1135-1144

40. Yang WH, Yu JH, Nakajima A et al (2004) Do antinuclear antibodies in primary biliary cirrhosis patients identify increased risk for liver failure? Clin Gastroenterol Hepatol Off Clin Pract J Am Gastroenterol Assoc 2:1116-1122

41. Rigopoulou EI, Davies ET, Bogdanos DP et al (2007) Antimitochondrial antibodies of immunoglobulin G3 subclass are associated with a more severe disease course in primary biliary cirrhosis. Liver Int 27:1226-1231

42. Courvalin JC, Worman HJ (1997) Nuclear envelope protein autoantibodies in primary biliary cirrhosis. Semin Liver Dis 17:79-90

43. Lozano F, Pares A, Borche L et al (1988) Autoantibodies against nuclear envelope-associated proteins in primary biliary cirrhosis. Hepatology 8:930-938

44. Bogdanos DP, Liaskos C, Rigopoulou EI et al (2006) Antimitochondrial antibodies in patients with systemic lupus erythematosus: revealing the unforeseen. Clin Chim Acta 373:183-184; author reply 185

45. Bogdanos DP, Pares A, Rodes J et al (2004) Primary biliary cirrhosis specific antinuclear antibodies in patients from Spain. Am J Gastroenterol 99:763-764; author reply 765
46. Gershwin ME, Mackay IR (2008) The causes of primary biliary cirrhosis: convenient and inconvenient truths. Hepatology 47:737-745

47. Lleo A, Selmi C, Invernizzi P et al (2009) Apotopes and the biliary specificity of primary biliary cirrhosis. Hepatology 49:871-879

48. Selmi C, Gershwin ME (2010) Autoantibodies in autoimmune liver disease: biomarkers versus epiphenomena. Gut 59:712-713

49. Vergani D, Bogdanos DP, Baum H (2004) Unusual suspects in primary biliary cirrhosis. Hepatology 39:38-41

50. Baum H, Bogdanos DP, Vergani D (2001) Antibodies to Clp protease in primary biliary cirrhosis: possible role of a mimicking T-cell epitope. J Hepatol 34:785-787

51. Bogdanos DP, Baum H, Grasso A et al (2004) Microbial mimics are major targets of crossreactivity with human pyruvate dehydrogenase in primary biliary cirrhosis. J Hepatol 40:31-39

52. Bogdanos DP, Baum H, Gunsar F et al (2004) Extensive homology between the major immunodominant mitochondrial antigen in primary biliary cirrhosis and Helicobacter pylori does not lead to immunological cross-reactivity. Scand J Gastroenterol 39:981-987

53. Bogdanos DP, Baum H, Sharma UC et al (2002) Antibodies against homologous microbial caseinolytic proteases $\mathrm{P}$ characterise primary biliary cirrhosis. J Hepatol 36:14-21

54. Bogdanos DP, Koutsoumpas A, Baum H et al (2006) Borrelia Burgdorferi: a new self-mimicking trigger in primary biliary cirrhosis. Dig Liver Dis 38:781-782; author reply 782-783

55. Bogdanos DP, McFarlane IG (2003) Cytochrome P450 2A6 meets P450 2D6: an enigma of viral infections and autoimmunity. J Hepatol 39:860-863

56. Bogdanos DP, Mieli-Vergani G, Vergani D (2000) Virus, liver and autoimmunity. Dig Liver Dis 32:440-446

57. Bogdanos DP, Muratori L, Bianchi FB et al (2000) Hepatitis C virus and autoimmunity. Hepatology 31:1380

58. Bogdanos DP, Pares A, Baum H et al (2004) Disease-specific cross-reactivity between mimicking peptides of heat shock protein of Mycobacterium gordonae and dominant epitope of E2 subunit of pyruvate dehydrogenase is common in Spanish but not British patients with primary biliary cirrhosis. J Autoimmun 22:353-362

59. Bogdanos DP, Vergani D (2009) Bacteria and primary biliary cirrhosis. Clin Rev Allergy Immunol 36:30-39

60. Granito A, Stanzani M, Muratori L et al (2008) LKM1-positive type 2 autoimmune hepatitis following allogenic hematopoietic stem-cell transplantation. Am J Gastroenterol 103:1313-1314

61. Gregorio GV, Choudhuri K, Ma Y et al (2003) Mimicry between the hepatitis $\mathrm{C}$ virus polyprotein and antigenic targets of nuclear and smooth muscle antibodies in chronic hepatitis $\mathrm{C}$ virus infection. Clin Exp Immunol 133:404-413

62. Invernizzi P, Miozzo M, Selmi C et al (2005) X chromosome monosomy: a common mechanism for autoimmune diseases. J Immunol 175:575-578

63. Kerkar N, Choudhuri K, Ma Y et al (2003) Cytochrome P4502D6(193-212): a new immunodominant epitope and target of virus/self cross-reactivity in liver kidney microsomal autoantibody type 1-positive liver disease. J Immunol 170:1481-1489

64. Lleo A, Selmi C, Invernizzi P et al (2008) The consequences of apoptosis in autoimmunity. J Autoimmun 31:257-262

65. Longhi MS, Hussain MJ, Bogdanos DP et al (2007) Cytochrome P450IID6-specific CD8 T cell immune responses mirror disease activity in autoimmune hepatitis type 2. Hepatology 46:472-484

66. Longhi MS, Ma Y, Bogdanos DP et al (2004) Impairment of $\mathrm{CD} 4(+) \mathrm{CD} 25(+)$ regulatory $\mathrm{T}$-cells in autoimmune liver disease. J Hepatol 41:31-37

67. Longhi MS, Ma Y, Mitry RR et al (2005) Effect of CD4+ $\mathrm{CD} 25+$ regulatory T-cells on CD8 T-cell function in patients with autoimmune hepatitis. J Autoimmun 25:63-71 
68. Ma Y, Thomas MG, Okamoto M et al (2002) Key residues of a major cytochrome P4502D6 epitope are located on the surface of the molecule. J Immunol 169:277-285

69. Muratori L, Bogdanos DP, Muratori P et al (2005) Susceptibility to thyroid disorders in hepatitis C. Clin Gastroenterol Hepatol 3:595-603

70. Vergani D, Choudhuri K, Bogdanos DP et al (2002) Pathogenesis of autoimmune hepatitis. Clin Liver Dis 6:727-737

71. Vergani D, Longhi MS, Bogdanos DP et al (2009) Autoimmune hepatitis. Semin Immunopathol 31:421-435

72. Wen L, Ma Y, Bogdanos DP et al (2001) Pediatric autoimmune liver diseases: the molecular basis of humoral and cellular immunity. Curr Mol Med 1:379-389

73. Abdulkarim AS, Petrovic LM, Kim WR et al (2004) Primary biliary cirrhosis: an infectious disease caused by Chlamydia pneumoniae? J Hepatol 40:380-384

74. Alvaro D, Invernizzi P, Onori P et al (2004) Estrogen receptors in cholangiocytes and the progression of primary biliary cirrhosis. J Hepatol 41:905-912

75. Amano K, Leung PS, Rieger R et al (2005) Chemical xenobiotics and mitochondrial autoantigens in primary biliary cirrhosis: identification of antibodies against a common environmental, cosmetic, and food additive, 2-octynoic acid. J Immunol 174:5874-5883

76. Amano K, Leung PS, Xu Q et al (2004) Xenobiotic-induced loss of tolerance in rabbits to the mitochondrial autoantigen of primary biliary cirrhosis is reversible. J Immunol 172:6444-6452

77. Hirschfield GM, Heathcote EJ, Gershwin ME (2010) Pathogenesis of cholestatic liver disease and therapeutic approaches. Gastroenterology 139:1481-1496

78. Jones DE (2007) Pathogenesis of primary biliary cirrhosis. Gut $56: 1615-1624$

79. Jones DE, Donaldson PT (2003) Genetic factors in the pathogenesis of primary biliary cirrhosis. Clin Liver Dis 7:841-864

80. Mackay IR, Whittingham S, Fida S et al (2000) The peculiar autoimmunity of primary biliary cirrhosis. Immunol Rev 174:226237

81. Mason A, Xu L, Shen Z et al (2004) Patients with primary biliary cirrhosis make anti-viral and anti-mitochondrial antibodies to mouse mammary tumor virus. Gastroenterology 127:1863-1864; author reply 1864-1865

82. McNally RJ, Ducker S, James OF (2009) Are transient environmental agents involved in the cause of primary biliary cirrhosis? Evidence from space-time clustering analysis. Hepatology 50:1169-1174

83. Shimoda S, Nakamura M, Ishibashi H et al (1995) HLA DRB4 0101-restricted immunodominant $\mathrm{T}$ cell autoepitope of pyruvate dehydrogenase complex in primary biliary cirrhosis: evidence of molecular mimicry in human autoimmune diseases. J Exp Med 181:1835-1845

84. Leung PS, Park O, Matsumura S et al (2003) Is there a relation between Chlamydia infection and primary biliary cirrhosis? Clin Dev Immunol 10:227-233

85. Xu L, Shen Z, Guo L et al (2003) Does a betaretrovirus infection trigger primary biliary cirrhosis? Proc Nat Acad Sci USA 100:8454-8459

86. Oertelt S, Lian ZX, Cheng CM et al (2006) Anti-mitochondrial antibodies and primary biliary cirrhosis in TGF-beta receptor II dominant-negative mice. J Immunol 177:1655-1660

87. Wakabayashi K, Lian ZX, Moritoki Y et al (2006) IL-2 receptor alpha $(-/-)$ mice and the development of primary biliary cirrhosis. Hepatology 44:1240-1249

88. Yang GX, Lian ZX, Chuang YH et al (2008) Adoptive transfer of $\mathrm{CD} 8(+) \mathrm{T}$ cells from transforming growth factor beta receptor type II (dominant negative form) induces autoimmune cholangitis in mice. Hepatology 47:1974-1982
89. Zhang W, Sharma R, Ju ST et al (2009) Deficiency in regulatory $T$ cells results in development of antimitochondrial antibodies and autoimmune cholangitis. Hepatology 49:545-552

90. Lazaridis KN, Juran BD, Boe GM et al (2007) Increased prevalence of antimitochondrial antibodies in first-degree relatives of patients with primary biliary cirrhosis. Hepatology 46:785-792

91. Bogdanos DP, Dalekos GN (2008) Enzymes as target antigens of liver-specific autoimmunity: the case of cytochromes P450s. Curr Med Chem 15:2285-2292

92. Smyk D, Cholongitas E, Kriese S et al (2011) Primary biliary cirrhosis: family stories. Autoimmune Dis 2011:189585

93. Smyk D, Rigopoulou EI, Baum H et al (2012) Autoimmunity and environment: am I at risk? Clin Rev Allergy Immunol 42:199-212

94. Smyk DS, Bogdanos DP, Kriese S et al (2012) Urinary tract infection as a risk factor for autoimmune liver disease: from bench to bedside. Clin Res Hepatol Gastroenterol 36(2):110-121

95. Smyk DS, Rigopoulou EI, Lleo A et al (2011) Immunopathogenesis of primary biliary cirrhosis: an old wives' tale. Immun Ageing I\&A 8:12

96. Brind AM, Bray GP, Portmann BC et al (1995) Prevalence and pattern of familial disease in primary biliary cirrhosis. Gut 36:615-617

97. Floreani A, Naccarato R, Chiaramonte M (1997) Prevalence of familial disease in primary biliary cirrhosis in Italy. J Hepatol 26:737-738

98. Jaup BH, Zettergren LS (1980) Familial occurrence of primary biliary cirrhosis associated with hypergammaglobulinemia in descendants: a family study. Gastroenterology 78:549-555

99. Jones DE, Watt FE, Metcalf JV et al (1999) Familial primary biliary cirrhosis reassessed: a geographically-based population study. J Hepatol 30:402-407

100. Tsuji K, Watanabe Y, Van De Water J et al (1999) Familial primary biliary cirrhosis in Hiroshima. J Autoimmun 13:171-178

101. Bogdanos DP, Smyk DS, Rigopoulou EI et al (2012) Twin studies in autoimmune disease: genetics, gender and environment. J Autoimmun 38:J156-J169

102. Invernizzi P, Miozzo M, Battezzati PM et al (2004) Frequency of monosomy $\mathrm{X}$ in women with primary biliary cirrhosis. Lancet 363:533-535

103. Selmi C, Invernizzi P, Zuin $M$ et al (2005) Genes and (auto)immunity in primary biliary cirrhosis. Genes Immun 6:543-556

104. Selmi C, Invernizzi P, Miozzo M et al (2004) Primary biliary cirrhosis: does X mark the spot? Autoimmun Rev 3:493-499

105. Milkiewicz P, Heathcote J (2004) Can Turner syndrome teach us about the pathogenesis of chronic cholestasis? Hepatology 40:1226-1228

106. Milkiewicz P, Heathcote J (2005) Primary biliary cirrhosis in a patient with Turner syndrome. Can J Gastroenterol 19:631-633

107. Selmi C, Mayo MJ, Bach N et al (2004) Primary biliary cirrhosis in monozygotic and dizygotic twins: genetics, epigenetics, and environment. Gastroenterology 127:485-492

108. Hirschfield GM, Invernizzi P (2011) Progress in the genetics of primary biliary cirrhosis. Semin Liver Dis 31:147-156

109. Hirschfield GM, Liu X, Xu C et al (2009) Primary biliary cirrhosis associated with HLA, IL12A, and IL12RB2 variants. N Engl J Med 360:2544-2555

110. Hirschfield GM, Liu X, Han Y et al (2010) Variants at IRF5TNPO3, 17q12-21 and MMEL1 are associated with primary biliary cirrhosis. Nat Genet 42:655-657

111. Tanaka A, Invernizzi P, Ohira H et al (2011) Replicated association of $17 q 12-21$ with susceptibility of primary biliary cirrhosis in a Japanese cohort. Tissue Antigens 78:65-68

112. Liu X, Invernizzi P, Lu Y et al (2010) Genome-wide metaanalyses identify three loci associated with primary biliary cirrhosis. Nat Genet 42:658-660 
113. Mells GF, Floyd JA, Morley KI et al (2011) Genome-wide association study identifies 12 new susceptibility loci for primary biliary cirrhosis. Nat Genet 43:329-332

114. Bogdanos DP, Smyk DS, Rigopoulou EI et al (2012) Smoking as a risk factor for autoimmune liver disease: what we can learn from primary biliary cirrhosis. Ann Hepatol Off J Mex Assoc Hepatol 11:7-14

115. Burroughs AK, Rosenstein IJ, Epstein O et al (1984) Bacteriuria and primary biliary cirrhosis. Gut 25:133-137

116. Bogdanos DP, Choudhuri K, Vergani D (2001) Molecular mimicry and autoimmune liver disease: virtuous intentions, malign consequences. Liver 21:225-232

117. Burroughs AK, Butler P, Sternberg MJ et al (1992) Molecular mimicry in liver disease. Nature 358:377-378

118. Van de Water J, Ishibashi H, Coppel RL et al (2001) Molecular mimicry and primary biliary cirrhosis: premises not promises. Hepatology 33:771-775

119. Shimoda S, Nakamura M, Shigematsu H et al (2000) Mimicry peptides of human PDC-E2 163-176 peptide, the immunodominant T-cell epitope of primary biliary cirrhosis. Hepatology 31:1212-1216

120. Gregorio GV, Choudhuri K, Ma Y et al (1999) Mimicry between the hepatitis B virus DNA polymerase and the antigenic targets of nuclear and smooth muscle antibodies in chronic hepatitis B virus infection. J Immunol 162:1802-1810

121. Bogdanos DP, McFarlane IG (2003) Cytochrome P450 2A6 meets P450 2D6: an enigma of viral infections and autoimmunity. J Hepatol 39:860-863

122. Bogdanos DP, Lenzi M, Okamoto M et al (2004) Multiple viral/ self immunological cross-reactivity in liver kidney microsomal antibody positive hepatitis $\mathrm{C}$ virus infected patients is associated with the possession of HLA B51. Int J Immunopathol Pharmacol 17:83-92

123. Smyk D, Mytilinaiou MG, Rigopoulou EI et al (2010) PBC triggers in water reservoirs, coal mining areas and waste disposal sites: from Newcastle to New York. Dis Markers 29:337-344
124. Butler P, Hamilton-Miller J, Baum H et al (1995) Detection of M2 antibodies in patients with recurrent urinary tract infection using an ELISA and purified PBC specific antigens. Evidence for a molecular mimicry mechanism in the pathogenesis of primary biliary cirrhosis? Biochem Mol Biol Int 35:473-485

125. Baum H, Bogdanos DP, Vergani D (2001) Antibodies to Clp protease in primary biliary cirrhosis: possible role of a mimicking T-cell epitope. J Hepatol 34:785-787

126. Mayo I, Arizti P, Pares A et al (2000) Antibodies against the $\mathrm{COOH}$-terminal region of $E$. coli $\mathrm{ClpP}$ protease in patients with primary biliary cirrhosis. J Hepatol 33:528-536

127. Bogdanos DP, Baum H, Vergani D et al (2010) The role of E. coli infection in the pathogenesis of primary biliary cirrhosis. Dis Markers 29:301-311

128. Bogdanos DP, Baum H, Grasso A et al (2004) Microbial mimics are major targets of crossreactivity with human pyruvate dehydrogenase in primary biliary cirrhosis. J Hepatol 40:31-39

129. Shimoda S, Van de Water J, Ansari A et al (1998) Identification and precursor frequency analysis of a common $\mathrm{T}$ cell epitope motif in mitochondrial autoantigens in primary biliary cirrhosis. J Clin Invest 102:1831-1840

130. Bogdanos DP, Baum H, Okamoto M et al (2005) Primary biliary cirrhosis is characterized by IgG3 antibodies cross-reactive with the major mitochondrial autoepitope and its Lactobacillus mimic. Hepatology 42:458-465

131. Bogdanos D, Pusl T, Rust C et al (2008) Primary biliary cirrhosis following Lactobacillus vaccination for recurrent vaginitis. J Hepatol 49:466-473

132. Bernier M, Njomnang Soh P, Lochet A et al (2012) Lactobacillus delbrueckii: Probable agent of urinary tract infections in very old women. Pathol Biol (Paris) 60(2):140-142

133. Darbro BW, Petroelje BK, Doern GV (2009) Lactobacillus delbrueckii as the cause of urinary tract infection. J Clin Microbiol 47:275-277

134. Varyani FK, West J, Card TR (2011) An increased risk of urinary tract infection precedes development of primary biliary cirrhosis. BMC Gastroenterol 11:95 